\title{
Diploid Males and Triploid Females of the Parasitic Wasp, Habrobracon pectinophorae Watanabe
}

\author{
By \\ Fumie Inaba \\ Zoological Institute, Kyoto Imperial University
}

Received December 21, 1938

In the parasitic wasp, Habrobracon juglandis (Ashmead), normal males develop from unfertilized, females from fertilized eggs as in other hymenoptera. Exceptional diploid males from fertilized eggs were first reported in 1921 by P. W. Whiting, and many works on such males have been published since by several authors. These works have confirmed that the diploid males appear from the crossings of closely related stocks, while those of un-related stocks fail to produce them. Such males are either completely sterile or produce a few triploid daughters which are also completely sterile. The diploidy of those males and the triploidy of such females have been shown genetically (A. R. Whiting '27, '28, M. M. Torvik '31), as well as cytologically (M. M. Torvik '33, M. Torvik-Greb '35), though the triploidy of the chromosomes has not yet been definitely determined.

In this paper, some data obtained for diploid males of the Japanese species, Habrobracon pectinophorae Watanabe, are reported. These males are mostly fertile, and their diploid nature, as well as the triploid nature of their daughters, has been proved cytologically.

The stocks used are derived from the culture of the wasp with Ephestia which are kept in the Government Agricultural Experiment Station in Tokyo and the Prefectural Agricultural Experiment Station in Sizuoka for the purpose of checking the famous pest of rice-plant, Chilo simplex.

In the stock culture derived from the Tokyo material a recessive mutant curved (cu) appeared. This factor affects the antennae, wings and tarsi. The antennae are curved near the base, owing to the fusion of a few segments (Figs. 4 and 6) ; the wings are reduced in length and have an indentation at the apex and the hairs are disarranged and give the wing surface a roughened appearance (Fig. 2) ; the tarsi are shortened and curved (Figs. 10-12). About twenty per cent of the males and a slightly higher percentage of the females with this factor in the homologous state become sterile. The viability of both the males and females is good. 
The other recessive mutant, white (wh), appeared also in the same stock. This factor changes the eye color that is black in the wild type into whitish. The fertility and viability are normal.

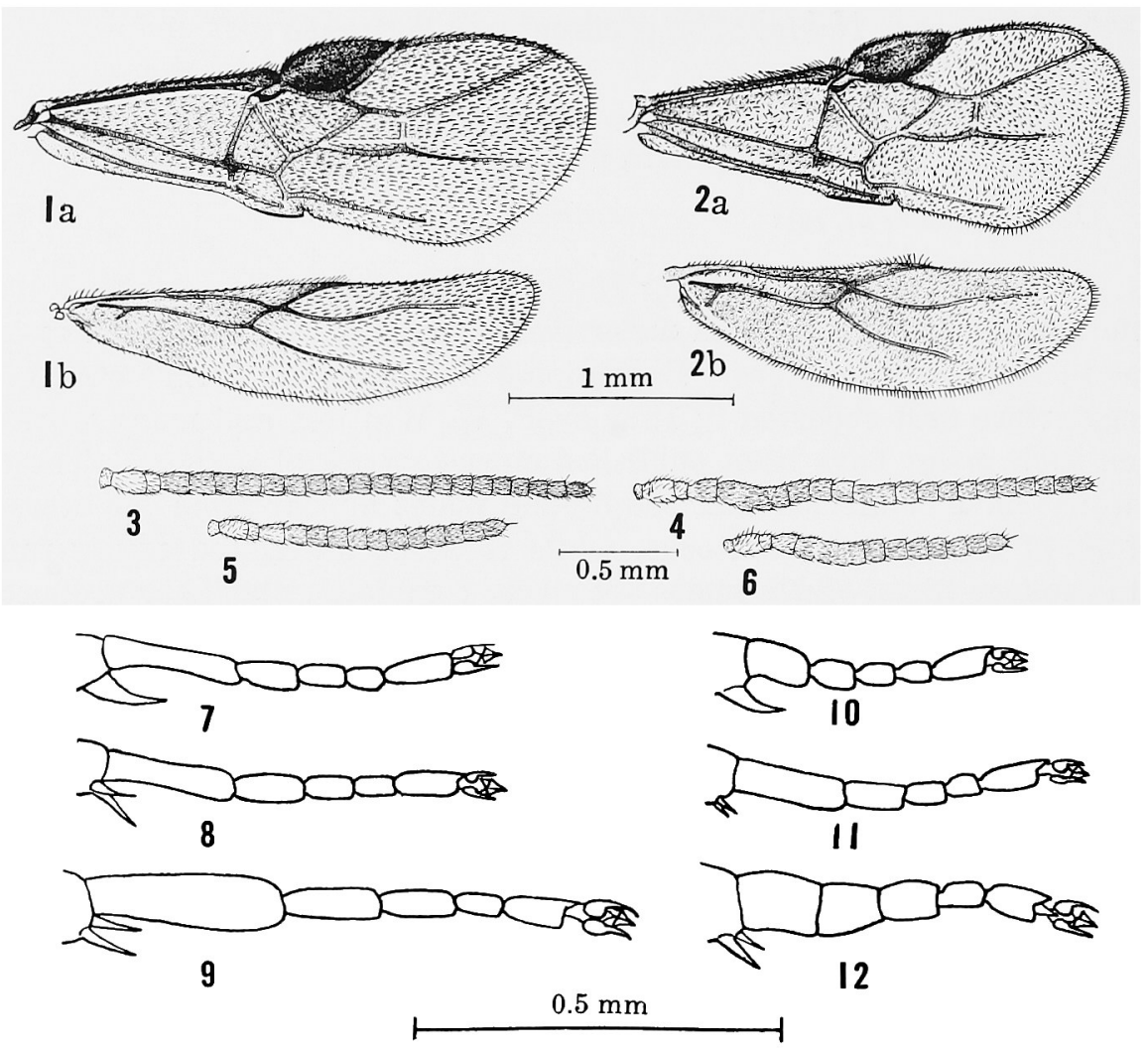

Figs. 1 and 2. Wings. 1, wild type; 2, curved. Figs. 3-6. Antennae. 3, wild type male; 4, curved male ; 5, wild type female; 6, curved female. Figs. 7-12. Tarsi. 7-9, wild type. 7, fore leg; 8, middle leg; 9, hind leg. 10-12, curved. 10, fore leg; 11, middle leg; 12, hind leg.

\section{Diploid Males}

Production: In this species also, just as in Habrobracon juglandis, the normal males develop parthenogenetically, and the females develop bisexually. Therefore, when recessive females are mated with wild type males, recessive males and wild type females are produced. Exceptional diploid males, if produced, receive dominant characters from their fathers, and are like females in their phenotype.

To obtain such diploid males, crossing experiments were made with curved females, white females and the double recessive white- 
curved females to their wild type brothers which were closely related to them, or to the wild type males from the related Tokyo stock, or to those from the un-related Sizuoka-, Taihoku- or Suigen (Tyōsen) stock. Table 1 indicates the summaries of the results obtained.

Table 1. Summary of data on the production of diploid males.

\begin{tabular}{|c|c|c|c|c|c|c|c|c|c|}
\hline \multicolumn{2}{|c|}{ Parents } & $\begin{array}{c}\text { Number } \\
\text { of } \\
\text { matings }\end{array}$ & $\begin{array}{l}\text { Matings } \\
\text { with } \\
\text { diploid } \\
\text { males }\end{array}$ & $\begin{array}{c}\% \\
\text { matings } \\
\text { with } \\
\text { diploid } \\
\text { males }\end{array}$ & $\begin{array}{c}\text { Diploid } \\
\text { males }\end{array}$ & $\begin{array}{c}\mathrm{Fe}_{-} \\
\text {males }\end{array}$ & $\begin{array}{l}\text { Ha- } \\
\text { ploid } \\
\text { males }\end{array}$ & $\begin{array}{c}\% \\
\text { diploid } \\
\text { males to } \\
\text { diploid } \\
\text { off- } \\
\text { spring } \\
\end{array}$ & $\begin{array}{c}\% \\
\text { diploid } \\
\text { off- } \\
\text { spring }\end{array}$ \\
\hline \multirow{4}{*}{$\operatorname{cu} x+$} & $\begin{array}{l}\text { Closely } \\
\text { related }\end{array}$ & 149 & 18 & $12.08+$ & 25 & 1742 & 1819 & $1.41+$ & $49.27+$ \\
\hline & Related & 63 & 3 & $4.76+$ & 3 & 923 & 767 & $0.32+$ & $54.70-$ \\
\hline & $\begin{array}{l}\text { Un- } \\
\text { related }\end{array}$ & 15 & 0 & 0 & 0 & 194 & 137 & 0 & $58.61+$ \\
\hline & Total & 227 & 21 & $9.25+$ & 28 & 2859 & 2723 & $0.97-$ & $51.46+$ \\
\hline \multirow{4}{*}{ wh $x+$} & $\begin{array}{l}\text { Closely } \\
\text { related } \\
\end{array}$ & 16 & 10 & 62.50 & 20 & 333 & 387 & $5.67-$ & $47.70+$ \\
\hline & Related & 13 & 5 & $38.46+$ & 11 & 315 & 245 & $3.37+$ & $57.09+$ \\
\hline & $\begin{array}{l}\text { Un- } \\
\text { related }\end{array}$ & 5 & 0 & 0 & 0 & 193 & 113 & 0 & $63.08-$ \\
\hline & Total & 34 & 15 & $44.12-$ & 31 & 841 & 745 & $3.56-$ & $53.93-$ \\
\hline $\begin{array}{c}\text { wh cu } \\
x+\end{array}$ & Related & 7 & 0 & 0 & 0 & 118 & 100 & 0 & $54.13-$ \\
\hline
\end{tabular}

As shown in this table, the highest ratio of the occurrence of the diploid males is obtained in the case of closely related matings, and the percentage of diploid males in diploid offspring is negatively correlated with that of the total diploid offspring, just as has been reported in $H$. juglandis (A. R. Whiting '25, P. W. Whiting \& R. L. Anderson '32). No diploid males arose from crosses of un-related stocks. It may be also noticed in the table that the ratio of the matings producing diploid males and the percentage of diploid males are both high in the case of white as compared with that of curved or of the double recessive females. The latter cross failed to produce diploid males, although the smallness of number of crosses should be admitted. These data seem to support the view presented by C. H. Bostian ('34) in $H$. juglandis that some hereditary factors induce the production of diploid males and give influence to their number produced.

External appearance: Some of the diploid males are normal in appearance, while others show abnormalities, such as the fusion of antennal segments in a different way from that shown by curved, 
the irregularity of sclerites like that reported in $H$. juglandis (A. R. Whiting '25, '27, M. M. Torvik '31).

Fertility: The fertility of 40 of the 59 diploid males obtained was tested. The males were mated with recessive females in most cases, or with wild type females in a few cases. Table 2 gives summaries of the results obtained.

Table 2. Summary of the fertility tests of the diploid males.

\begin{tabular}{c|c|c|c|c|c|c|c|c}
\hline & $\begin{array}{c}\text { Diploid } \\
\text { males tested }\end{array}$ & Fertile & $\begin{array}{c}\% \\
\text { fertile }\end{array}$ & $\begin{array}{c}\text { Number of } \\
\text { matings }\end{array}$ & Fertile & Males & $\begin{array}{c}\text { Fe- } \\
\text { males }\end{array}$ & $\begin{array}{c}\% \text { Fe- } \\
\text { males }\end{array}$ \\
\hline curved & 24 & 19 & 79.17 & 52 & 31 & 683 & 158 & $18.79-$ \\
\hline white & 16 & 9 & 56.25 & 29 & 10 & 218 & 29 & $11.74+$ \\
\hline
\end{tabular}

As shown in the table, about 80 per cent of the diploid sons of curved females and about 56 per cent of those of white females were fertile, although the number of daughters obtained was very small as compared with normal males. Thus the fertility of diploid males of this species seems to be much higher than that of $H$. juglandis in which about 75 per cent of diploid males obtained from orange females (A. R. Whiting '25), and 90 per cent of those obtained from various mutant females ( $M$. M. Torvik '31) were sterile. It is also apparent that higher fertility is found in the case of curved than in the case of other mutant stocks. As M. M. Torvik pointed out ('31), it is likely that the fertility of diploid males differs with the hereditary factor involved and the stock used.

\section{Triploid Females}

In all 187 daughters were obtained from diploid males. All of them showed dominant characters and many of them were normal in appearance and size, while some of them had irregular abdominal sclerites. One had a very small eye on the left side, and another lacked the right half of prothorax and a fore leg. These triploid females, without exception, stung host catapillars and laid eggs exactly like normal females. Nevertheless, almost all of their eggs failed to hatch, though the embryos within developed fairly well. Only twelve of the 187 females produced fourteen eggs which developed into larvae. These eggs were all produced by the daughters of diploid sons of the curved females, and their mothers had been allowed to mate with their curved brothers. Of these fourteen larvae, eight died in the larval or prepupal stage, four died in the pupal stage and two became adults. The phenotypes of the six individuals determined are shown in Table 3. 
The two adult males, curved and wild type, were mated with curved females. The former bred like an ordinary curved male, producing 4 curved females. The latter produced 14 wild type females, 4 of which were tested. These gave 25 curved males, 26 wild type males, one curved female and one wild type female. Therefore, the wild type male bred like a normal male.
Table 3. Offspring produced by triploid females, which developed into larvae.

\begin{tabular}{l|cccc}
\hline & cuo & $+\sigma^{\circ}$ & $\mathrm{cu}$ o & + + \\
\hline Larvae & \multicolumn{4}{|c}{4} \\
\hline Prepupae & \multicolumn{4}{|c}{4} \\
\hline Pupae & 1 & 1 & 1 & $1 *$ \\
\hline Adults & 1 & 1 & &
\end{tabular}

* This wild type female was a granddaughter of a diploid male mated with a wild type female.

\section{Cytological Evidence for Diploidy and Triploidy}

The chromosome complex of $H$. juglandis was studied by M. M. Torvik ('33) and M. Torvik-Greb ('35). The haploid number is 10. In diploid males, the diploid number of chromosomes was observed, while in their daughters, larger numbers were counted, but they have not yet been determined exactly.

In Habrobracon pectinophorae Watanabe the chromosome complexes of the normal males and females, diploid males and of their daughters were studied in aceto-carmine preparations. The gonads of male young pupae and of females just before eclosion were used. These were very favorable materials for the study of spermatogonial or oögonial divisions.

In the spermatogonial metaphase of haploid males, 10 chromosomes (Fig. 13), and in the oögonial metaphase of normal females, 20 chromosomes were seen (Fig. 14).

In the spermatogonial metaphase plates of diploid males, there are apparently 20 chromosomes which seem to be 10 pairs of homologous ones, though they do not always lie in pairs (Figs. 15 and 16).

The triploid females are expected to have 30 chromosomes. Figs. 17 and 18 show the metaphase plates' of oögonial divisions from such triploid females, which include 30 chromosomes. It is a curious thing that in the oögonial cells of triploid females, not only triploid, but also haploid and diploid numbers of chromosomes have been counted.

According to M. Torvik-Greb ('35), the haploid set of chromosomes in the normal male of $H$. juglandis consists of four V's, two $L ' s$, two J's, one small $V$ and one small rod. In this species, however, there seem to be five V's, two L's, perhaps two J's and one small V instead of a small rod. 


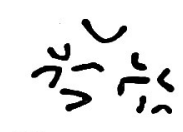

13

15

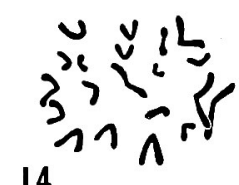

14
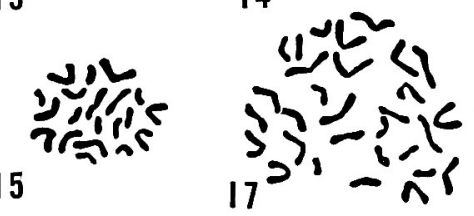

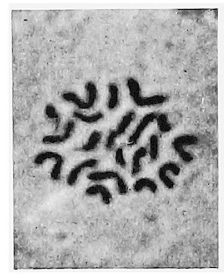

16

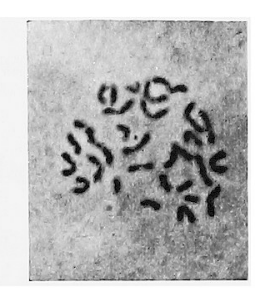

18
Figs. 13-18. Chromosomes of Habrobracon pectinophorae. All figures were drawn with the aid of a camera lucida at a magnification of ca. 2000 diameters. 13, spermatogonial metaphase from normal haploid males; 14 , oögonial metaphase from normal diploid females; 15, spermatogonial metaphase from diploid males; 16 , photomicrograph of the material from which Fig. 15 was drawn $(\times 2400)$. 17, oögonial metaphase from triploid females; 18, photomicrograph of the material from whicb Fig. 17 was drawn $(\times 1600)$.

\section{Gynandromorph and Haplo- diploid Mosaic Male}

One gynandromorph with diploid male parts was found in a cross of a curved female with a wild type male, which mating gave, in addition, 26 curved males, $27 \mathrm{fe}$ males and one diploid male. In this gynandromorph, the antennae were of the wild type male, therefore diploid, and both the wings and tarsi were of the wild type, but it could not be determined if these were of the male or female type. The abdomen was entirely female, but the mating behaviour was of a typical male. A diploid male was also produced by a white female heterozygous for curved, mated with a wild type male. He had black eyes, and the wings and legs of the wild type, but his antennae were curved, therefore matroclinous. This apparently haplo-diploid mosaic male was very feeble, and failed to produce offspring. The cytological study of the testis showed it to be diploid.

\section{Summary}

1. The production of diploid males in the parasitic wasp, Habrobracon pectinophorae Watanabe was studied by using two recessive mutant characters, white and curved.

2. The frequency varied according to the hereditary factor involved. Higher frequency was obtained in the case when white was used than in other cases.

3. The fertility of diploid males is very high in this species as compared with the American species, H. juglandis. Especially high fertility was found in the case of curved. Therefore, the fertility of diploid males also depends on the hereditary factor involved. 
4. The daughters of the diploid males laid many eggs which, however, failed to hatch, though embryos were formed within.

5. The chromosome complexes of all the types of males and females were studied. The diploidy of biparental males and triploidy of their daughters have been confirmed definitely. In the triploid females, haploid, diploid and triploid chromosomes seem to be mixed in the oögonial cells.

6. A gynandromorph with diploid male parts and a haplodiploid mosaic male are described.

I wish to express my heartfelt gratitude to Prof. Dr. T. Komai for his suggestions and kind guidance during the course of this work. I am also indebted to Messrs. T. Hama, K. Iyatomi, J. Sonan and M. Nakayama for their kindness in supplying me with the material.

\section{Literature Cited}

Bostian, C. H., 1934. Biparental Males and Biparental Ratios in Habrobracon. Biol. Bull., 66.

Torvik, M. M., 1931. Genetic Evidence for Diploidism of Biparental Males in Habrobracon. Biol. Bull., 61.

- 1933. Chromosomes of Habrobracon. Proc. Penn. Acad. Sci., 7.

Torvik-Greb, M., 1935. The Chromosomes of Habrobracon. Biol. Bull., 68 .

Whiting, A. R., 1925. The Inheritance of Sterility and of Other Defects Induced by Abnormal Fertilization in the Parasitic Wasp, Habrobracon juglandis (Ashmead). Geneties, 10.

- 1927. Genetic Evidence for Diploid Males in Habrobracon. Biol. Bull. 53.

- 1928. Genetic Evidence for Diploid Males in Habrobracon. Am. Nat., 62.

Whiting, P. W., 1921. Genetics of an Orange-eyed Mutation and the Production of Mosaic Males from Fertilized Eggs. Biol. Bull., 41.

- and R. L. Anderson, 1932. Temperature and Other Factors Concerned in Male Biparentalism in Habrobracon. Am. Nat., 66. 